\title{
marges Marges
}

revue d'art contemporain Revue d'art contemporain

13 | 2011

Langage(s) de l'œuvre et de l'art

\section{«Chefs-d'œuvre? »}

Metz, Centre Pompidou Metz, 12 mai 2010 - 12 septembre 2011

\section{Jérôme Glicenstein}

\section{(2) OpenEdition}

\section{Journals}

Édition électronique

URL : http://journals.openedition.org/marges/455

DOI : $10.4000 /$ marges. 455

ISSN : 2416-8742

Éditeur

Presses universitaires de Vincennes

\section{Édition imprimée}

Date de publication : 1 septembre 2011

Pagination : 140-141

ISBN : 978-2-84292-343-3

ISSN : $1767-7114$

Référence électronique

Jérôme Glicenstein, « "Chefs-d'œuvre ? » », Marges [En ligne], 13 | 2011, mis en ligne le 15 septembre 2012, consulté le 22 septembre 2020. URL : http://journals.openedition.org/marges/455; DOI :

https://doi.org/10.4000/marges.455 


\section{Chefs-d'œuvre?}

12 mai 2010 - 12 septembre 2011

Centre Pompidou Metz

«Chefs-d'œuvre? », l'exposition inaugurale du Centre Pompidou Metz, avait semble-t-il pour objectif d'asseoir la réputation de cette nouvelle institution. Elle rassemblait donc plus de 800 œuvres et objets divers issus, pour la plupart, des collections du MNAM, tout en occupant l'ensemble du bâtiment. Parcourant l'histoire de l'art en diagonale et abordant à peu près tous les champs possibles et imaginables de la création (peinture, sculpture, installations, arts graphiques, photographie, vidéo, œuvres sonores, cinéma, architecture, design, etc.), il s'agissait, selon les différents documents de présentation, « d'interroger la notion de chef-d'œuvre, son histoire et son actualité », sachant que cette notion avait été, disait-on, largement délaissée par les artistes de ces dernières décennies.

L'exposition suivait un découpage par étage. Au rez-de-chaussée, "Chefs-d'œuvre dans l'histoire », proposait un panorama très large de la notion de chef-d'œuvre à travers les âges, de la Renaissance à l'époque moderne. Les objets étaient présentés au sein de sous-sections thématiques: Chefs-d'œu- vre au Moyen-Âge, Autour du Chef-d'œuvre inconnu, Virtuosités, Chefs-d'œuvre d'hier, Les primitifs du $20^{\mathrm{e}}$ siècle, etc. Le parcours s'ouvrait sur La Tristesse du roi de Matisse et aboutissait aux trois Bleu de Miro. Bien que ces deux pôles aient pu faire croire à une focalisation sur l'art moderne, il n'en était rien puisqu'on passait des œuvres de Ligier Richier et Georges de La Tour à une évocation du Chef-d'œuvre inconnu de Balzac, puis à un lustre produit aux cristalleries Saint-Louis (fleuron de l'artisanat lorrain), avant d'aborder une section sur les Réalismes des années 1930 et les décors des Delaunay.

Au premier étage, « Histoires de chefs-d'œuvres" égrenait une suite de salles consacrées à des mouvances avant-gardistes (Fauvisme, Dada, Surréalisme, Nouveaux réalistes...), mettant en valeur certains artistes qui leur avaient été associés (Duchamp, Tatline, Raysse, César, Ben...). C'était sans doute la partie la plus confuse. D'autant plus qu'il y avait là à la fois des objets pouvant explicitement prétendre au titre de "chef-d'œuvre" (la maquette du Monument à la $3^{e}$ interna- 
tionale de Tatline) et d'autres plus ambivalents (les dessins d'André Raffray inspirés de Duchamp, par exemple), voire opposés par principe à l'idée même de chef-d'œuvre (les ready-made de Duchamp).

Au deuxième étage, "Rêves de chefs-d'œuvre ", était constitué de trois galeries parallèles communiquant entre elles. La première, plongée dans le noir, donnait à voir des suites de cartels établissant des liens entre divers documents. Face à ceux-ci, une ouverture horizontale permettait d'apercevoir une deuxième galerie, très éclairée, présentant une "parade de chefs-d'œuvre", les uns à côté des autres - sans que l'on sache très bien s'il s'agissait de les mettre en valeur ou juste de les accumuler. Il y avait là à la fois une suite d'œuvres de Kandinsky, Picasso, Ernst, Pollock, Arp, Giacometti, etc., et en vis-à-vis un alignement de meubles de design suspendus en l'air. La troisième galerie, que l'on n'apercevait pas immédiatement, présentait une suite de maquettes, plans, dessins et vues d'architectures de musées réalisés en France depuis la création du MNAM en 1937. Cette présentation s'achevait de manière assez prévisible sur le projet de Centre Pompidou Metz.

$\mathrm{Au}$ troisième étage, la dernière section, "Chefs-d'œuvre à l'infini », était principalement composée de vitrines regroupant des ensembles hétérogènes: la bibliothèque d'André Malraux, un ensemble de publications artistiques (livres et revues d'artistes) réalisées au cours du $20^{\mathrm{e}}$ siècle, voire d'autres séries: les pages de Jazz de Matisse, ou la reconstitution d'une vitrine ethnographique créée par le muséologue Georges-Henri Rivière pour le Musée des Arts et Traditions Populaires. La dernière chose que l'on voyait, tout au bout de la dernière galerie, était une vue de la cathédrale de Metz (considérée sans doute, elle aussi, comme un chef-d'œuvre).
Il est évidemment très difficile de rendre compte d'une exposition aussi complexe et ambitieuse que "Chefs-d'œuvre? ». On l'aura compris, le point d'interrogation du titre témoigne bien de l'embarras qu'avait dû poser un tel sujet à ses organisateurs. De fait, l'exposition multipliait les signaux contradictoires: entre glorification de certains artistes (dont un certain nombre de Lorrains) et contestation de la notion même de chef-d'œuvre. On avait ainsi, à la fois des objets largement considérés comme des chefs-d'œuvre (Kandinsky, Picasso, Matisse) et des objets au statut plus incertain: la cane de Balzac, une tapisserie réalisée d'après Guernica, un lustre en cristal... La scénographie renvoyait à la même incertitude : certaines parties faisaient penser à un labyrinthe (rez-de-chaussée), d'autres à un couloir du métro ( $2^{\mathrm{e}}$ étage), d'autres encore à une brocante (le $1^{\mathrm{er}}$ étage). Certaines œuvres étaient présentées isolées, sacralisées et dans le noir; d'autres sous forme d'accumulation et sous une lumière peu flatteuse. On sent bien - en consultant le catalogue, par exemple - qu'une perspective critique était au fondement du projet; on sent bien également que les organisateurs ont dû prendre en compte des enjeux de toute nature, pas nécessairement artistiques d'ailleurs. Se pourrait-il que le curieux lustre monumental des cristalleries Saint-Louis ait été exposé pour faire plaisir à une entreprise partenaire de l'opération? Nous ne nous prononcerons pas. L'exposition a-t-elle été réussie? Peutêtre ne faut-il pas poser ce genre de question. En tout cas, si l'on s'en tient aux chiffres de fréquentation, il n'y a pas de doute: c'est un large succès. Mais, outre le fait qu'il s'agit au moins pour partie d'un succès de curiosité on peut tout de même s'interroger sur ce que les visiteurs en auront pensé et retenu.

\section{Jérôme Glicenstein}

